\title{
Assessing Customer Satisfaction and Brand Awareness of Branded Bread
}

\author{
Smitha Nair \\ Food Safety Consultant, India
}

\begin{abstract}
The bread market is growing at about 5\% per annum, according to the Ministry of Food Processing Industries. $85 \%$ bread production is in the hands of the unorganized sector. With a lot of competition building up to tap this potential market, the onus lies with the customer, who will turn to the brand which offers him complete satisfaction. This paper studies the factors which lead to customer satisfaction and brand awareness, by a random sampling of 100 customers in Cochin. The paper analyses customer satisfaction of a particular bread brand - Elite Bread and attempts to find out how well known it is to the customers, compared to its competitors. Limitations of the study and recommendations to improve customer satisfaction are put forth.
\end{abstract}

Keywords: Branded bread, customer satisfaction, brand awareness, attributes ranking, preference rating.

\section{Introduction}

Although India is an agricultural country, its food processing industry accounts for a small proportion (only $12 \%$ of the added value) of its manufacturing industry compared to those of other developing countries. A large proportion of India's food processing industry is therefore made up of independent businesses and other small-scale companies. Production by large corporations accounts for only about $20 \%$ of the total. With a huge population of 1.08 billion and population growth of about $1.6 \%$ per annum, India is a large and growing market for food products. Its 350 million strong urban middle class with its changing food habits poses a huge market for agricultural products and processed food.

According to the Ministry of Food Processing Industries, India (MOFPI), the processed food market, accounts for 32 per cent of the total food market. $85 \%$ of the total bread produced in India is by the unorganized sector. The size of the bread market is estimated at Rs 15 billion. Within the organized sector, Modern Foods, Brittania, Candico, Elite Bread and a host of others with a small market presence together account for only $15 \%$ of the total bread production. The demand for bread has been rising from Rs.6.42 billion in 1990-91 to Rs.21.10 billion in 2009-2010 and is expected to reachRs.26.90 billion in 2014-15. The Bread market is estimated to be growing at around 5\% per annum from 2009-10 to 2014-15, . The major bread segments include Milk Bread (85\%), Brown Bread (10\%) and 3\% Fruity Bread and Nutritional and other speciality 2\%. The perishable nature of the bread has led to a lot of problems, like the lack of a well developed retail network to deal with the distribution issues, hence the success of small time unorganized units in supply of bread, especially in the rural markets (Krishnamurthy, 2000).

As the number of competitors builds up in the industry, it is evident that the onus is now on the customers who are waking up to the fact that they have the right not only to have access to quality foods, but also to safe and convenience foods, hygienically prepared, and free from any contamination or adulteration. The firm, whose products will give maximum satisfaction to the consumers, will rule the roost. As is the norm in today's competitive era, the final goal of "satisfying" the customer with the product has progressed to "delighting" the customer. It is against this backdrop that this paper proposes to assess the customer satisfaction and brand awareness of the branded bread produced by Elite Breads Pvt Ltd vis-à-vis other bread brands, by the customers in Cochin.

\section{Research Methodology}

For this study, use of both primary as well as secondary data is done. The primary data sources are the customers using these products categories respectively. Primary data is also collected from the retailers in order to understand buying behaviour and product demand patterns. The secondary data made use of include statistics released by the Ministry of Food Processing Industries regarding the bread industry. Previous market research studies done by various governmental agencies APEDA, as well as private industry agencies and foreign agencies are also used for forming a general framework of the external environment in which the firm's products are competing. The methods employed for data collection include observation of buyer behaviour at retail shops and supermarkets, direct interview methods, use of a structured questionnaire and shopping mall intercept.

For the classification, analysis and interpretation of the primary data collected, several tools have been used. For summarizing the data, frequency distribution and measures of central value (mean, median and mode) 
were used. Measures of dispersion like Standard Deviation and cross tabulation are used. To reveal the underlying or latent factors that determine the relationship between the observed data, the semantic differential scales are employed to measure attitudes of customers towards different competitor brands in the three segments of bread, cake and packaged Atta. The statistical analysis has been done with the help of the SPSS software. For sampling, the method of stratified random sampling has been employed.The final sample size of 100 was utilized for data analysis.

\subsection{Customer satisfaction and Brand awareness}

Customer satisfaction is one of the most studied areas of marketing, and is perhaps the most important area of focus of organizations world over. If customers are satisfied with a product, they will buy it again and again, show brand loyalty and pass on the good word to others, but if on the other hand, they are dissatisfied with the product, they may either switch over to other brands, or may complain and show their displeasure to the firm initially and to others, which may harm the company in the long run (Peter and Olson, 2005).

Customer Satisfaction has been defined variously as an outcome and as a process. The outcomes of customer satisfaction are increased use, repeat purchase, brand loyalty or brand switching, while the process includes the customer decision making process, the superior expected value of the brand over others, the sales and the perceived value delivered (Howard \& Sheth, 1969; Engel \& Blackwell, 1982). Customer satisfaction is therefore the performance-expectations index, wherein if there is a match, the customers are satisfied, and a mismatch will mean customers are dissatisfied, so firms need to ensure that atleast the performance is equal to the expectations, and if possible exceed it.

Thus the very existence of a firm depends on how satisfied its customers are with its products and services. If the brand is able to satisfy the customer and develop a psychological attachment in him to the brand, then the customer would stay loyal to it, no matter what enticement the competition has to offer. Such customers would in turn pass on their experience with the brand to others who might be tempted to try it. These word-of mouth communications are more valuable to the firm than any advertisements, therefore firms always try to create committed customers rather than satisfied customers.

\section{Results and Discussion}

Marketers are always interested in finding out which member of the family takes the decision whether to buy a product or not, and if the decision is made in favour of buying the product, then the next decision to be made is with regard to the brand to be bought. This is necessary to find out who needs to be influenced in order for the product to be demanded. Buying decisions, in the context of marital power structure can be autonomic (where an equal number of decisions are made by each spouse), husband dominant, wife dominant, or syncratic where both husband and wife make most decisions jointly.

The study reveals that $35 \%$ of the respondents answered Mother/Wife to the question "Which member of your family makes brand decisions while purchasing?" while the answer Joint decisions also notched up an equal percentage. The decisions therefore are equally syncratic and wife dominant. Hence, the focus of target for the firm should be the female population, housewives and workingwomen alike. The above findings are shown in TABLE.1.

TABLE 1. Family Decision Maker While Purchasing Bread Brands
\begin{tabular}{|l|l|l|l|}
\hline Decision maker & Frequency & Percent & Cumulative Percent \\
\hline Father/husband & 15 & 15.0 & 17.0 \\
\hline Mother/wife & 35 & 35.0 & 52.0 \\
\hline Son/Daughter & 10 & 10.0 & 62.0 \\
\hline Joint Decision & 35 & 35.0 & 97.0 \\
\hline Others & 3 & 3.0 & 100.0 \\
\hline Total & 100 & 100.0 & \\
\hline
\end{tabular}

\section{Measuring Brand Awareness And Customer Satisfaction}

Brand awareness refers to product associations induced in the customers mind after repeated exposure to the product by way of advertisements etc. Studies reveal that the more the customer is made aware of the brand, the more will his desire to possess the brand go up. This indicates that brands are much more than bundles of features, rather they trigger feelings of associations with the brand inside the customer's mind and motivate him to buy the brand and experience it. The success of a marketing program is defined on the basis of the response to one basic question - "how satisfied were you with the product/service today?" Therefore keeping this in mind, a structured questionnaire was evolved to test the consumer satisfaction for the Elite products with respect to its competitors. The findings on brand awareness, brand recall, point of purchase, analysis of each product attributes, preference ranking, purchase quantity, rating of Elite products, and 
suggestions for improvement put forward by consumers, are as enumerated below for each of the three product categories of bread.

\subsection{Measuring Brand Equity}

Brand equity acquires different connotations when different people use it. It has been defined differently from different points of view. The definitions have been classified under 3 headings namely Costbased, Price-based and Consumer-based views.

\subsubsection{Customer-Based Brand Equity}

An attempt is made here to study the brand equity vis-à-vis the customer- based method alone, using brand recall and attribute-oriented approach. An approach of measuring brand equity is making the customer's knowledge of the brand the focus. Brand knowledge can be expressed as a sum of brand awareness and brand image. Each of the parameters (i.e. brand recall/strength of brand associations/attitudes/user image) can be measured on a 1 to 10 scale. A weighted sum of these parameters will be the measure of brand equity.

\subsubsection{Brand Recall}

Brand recall is measured by asking customers top-of-mind awareness questions like "Which are the top brands that come to your mind when you think of Elite?" All the respondents had heard of the company Elite Food Products Ltd. The brand recall rates of the respondents for the different products offered by the company revealed that Elite Sweet bread is the most popular product of the firm (91\% recall rate), while Elite Round Loaf is the least popular product (41\%).

\subsection{Brand Awareness And Buying Patterns For Bread \\ 4.2.1 Point Of Purchase}

It was seen that in the case of buying decisions regarding bread, $42 \%$ of the respondents, bought their bread from bakeries, while $17 \%$ were not particular about the point of purchase. $12 \%$ of the respondents purchased their breads from Margin Free supermarkets only, while another $10 \%$ were regular customers of other local supermarkets and bought their bread there (Table.2).

TABLE 2. Point of Purchase of Bread Brands

\begin{tabular}{|l|l|l|l|}
\hline POINT OF PURCHASE - BREAD & Frequency & Percent & Cumulative \% \\
\hline Margin Free Supermarket only & 12 & 12.0 & 12.0 \\
\hline Margin free Market \& bakeries & 3 & 3.0 & 15.0 \\
\hline Margin Free Market, Bakeries \& other supermarkets & 2 & 2.0 & 17.0 \\
\hline Margin free Markets, Bakeries \& Others & 1 & 1.0 & 18.0 \\
\hline Margin Free Market \& Ordinary Retail outlets & 2 & 2.0 & 20.0 \\
\hline Bakeries only & 42 & 42.0 & 62.0 \\
\hline Bakeries \& Other Supermarkets & 1 & 1.0 & 63.0 \\
\hline Bakeries \& Ordinary retail Outlets & 1 & 1.0 & 64.0 \\
\hline Other Supermarkets only & 9 & 9.0 & 73.0 \\
\hline Ordinary Retail Outlets only & 10 & 10.0 & 83.0 \\
\hline Not Particular about Location & 17 & 17.0 & 100.0 \\
\hline Total & 100 & 100.0 & \\
\hline
\end{tabular}

\subsubsection{Customer Perception Of Top Of Mind Bread Brands}

The customers were asked to rank the top of mind bread brands. The figure below (Fig.1) shows the different product ratings. The survey revealed that the top of mind bread brand is Modern Bread (71\%), while Elite Bread occupies the second place at $16 \%$. The rest of the top of mind share is filled with local brands, such as Best Bakers, Iris, Regal etc.

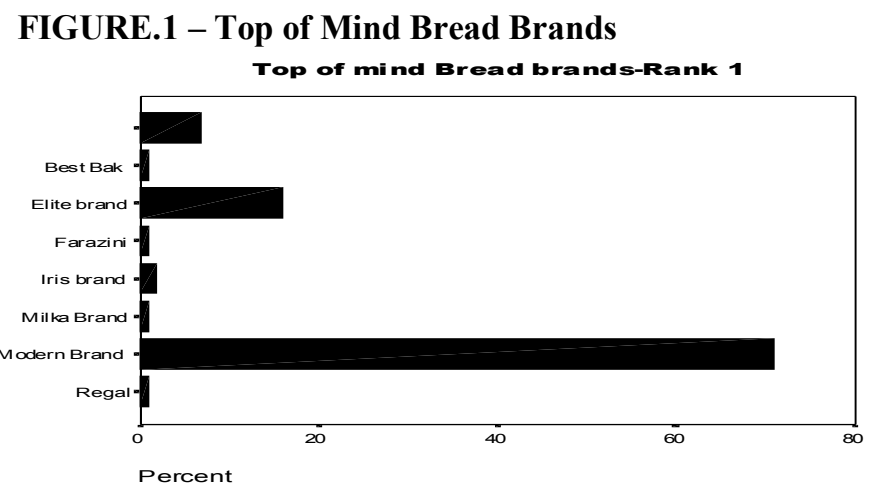




\subsubsection{Attribute Ranking for Bread by Consumers}

As part of the consumer satisfaction survey, respondents were also asked to rank 13 attributes, according to the importance of the factors they attributed to the brands they buy. The attributes include Low Price, Brand name, Freshness, Date of manufacture, Softness, Taste, Good Quality, Variety/Value addition, Colour, Availability, Packaging, Whole wheat $\%$ and Other factors (specified by the respondent).

The following Fig. 2 shows the ranking of the above attributes for bread. Freshness and good quality are the most sought for attributes ( $13 \%$ each), followed by taste (12\%), softness, date of manufacture (11\% each), brand name $(10 \%)$ etc. Low price was accorded only $6 \%$ and was considered less important, while packaging was considered unimportant and was accorded only $2 \%$. Table 3 gives the frequency, mean, maximum, minimum and standard deviation. The attribute freshness is the most important attribute, with frequency score 95 out of the total 100 and a minimum value of 7 on a 12-point scale.

Fig 2 Ranking of Factors for Bread by Customers

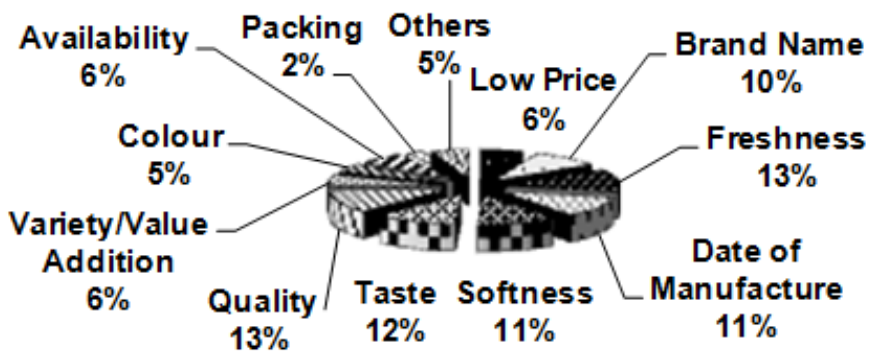

Table.3 - Descriptive Statistics For Attributes Related To Bread

\begin{tabular}{|l|c|c|c|c|c|}
\hline & $\mathrm{N}$ & Minimum & Maximum & Mean & Std. Deviation \\
\hline Good Quality & 95 & 2.00 & 13.00 & 11.4526 & 2.0041 \\
\hline Freshness & 95 & 7.00 & 13.00 & 11.4211 & 1.6017 \\
\hline Date of manufacture & 88 & 3.00 & 13.00 & 11.0795 & 2.0966 \\
\hline Taste & 93 & 5.00 & 13.00 & 10.7527 & 1.8097 \\
\hline Softness & 90 & 6.00 & 13.00 & 10.7111 & 1.9035 \\
\hline Brand name & 91 & 4.00 & 13.00 & 9.3297 & 2.3854 \\
\hline Whole wheat \% & 28 & 2.00 & 13.00 & 7.3214 & 3.1862 \\
\hline Variety/Value addition & 74 & 2.00 & 13.00 & 6.9865 & 3.0091 \\
\hline Availability & 78 & 2.00 & 13.00 & 6.9615 & 2.8624 \\
\hline Packaging & 67 & 2.00 & 13.00 & 6.9104 & 2.9885 \\
\hline Low Price & 80 & 2.00 & 13.00 & 6.6125 & 2.5974 \\
\hline Colour & 74 & 2.00 & 13.00 & 6.0405 & 2.3258 \\
\hline Other & 7 & 1.00 & 13.00 & 5.7143 & 4.5356 \\
\hline Valid N (listwise) & 4 & & & & \\
\hline
\end{tabular}

\subsubsection{Preference Rating For Bread Brands}

The following figure (Fig.3) shows the preference pattern governing the usage of the different bread brands. The brand with the highest percent shows greatest frequency of usage by the respondents. Here, both Elite Sweet Bread and Modern Sweet Bread share 14\% each of the respondent preference share. Elite White Bread shows a preference score of $13 \%$, showing that it is the next most preferred bread brand for consumption, followed by Elite Fruity Bread and Modern Family Bread, at 11\% each.

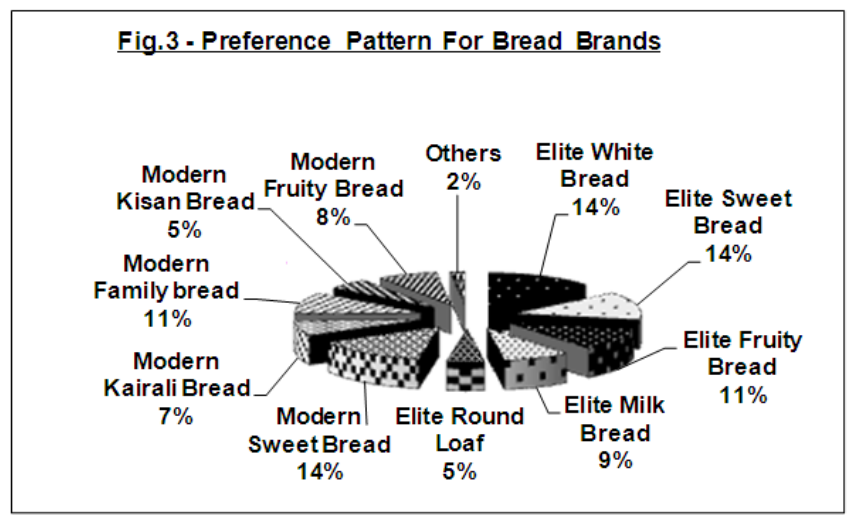




\section{Purchase Frequency for Bread Buying}

Nearly $42 \%$ of the respondents purchased bread on a weekly basis, while $19 \%$ purchased bread once in a fortnight. $19 \%$ of the respondents bought bread once in a month, while $19 \%$ were rare purchasers of bread and $1 \%$ were non-consumers for bread (Fig.4).

FIGURE4. PURCHASE Frequency for Bread

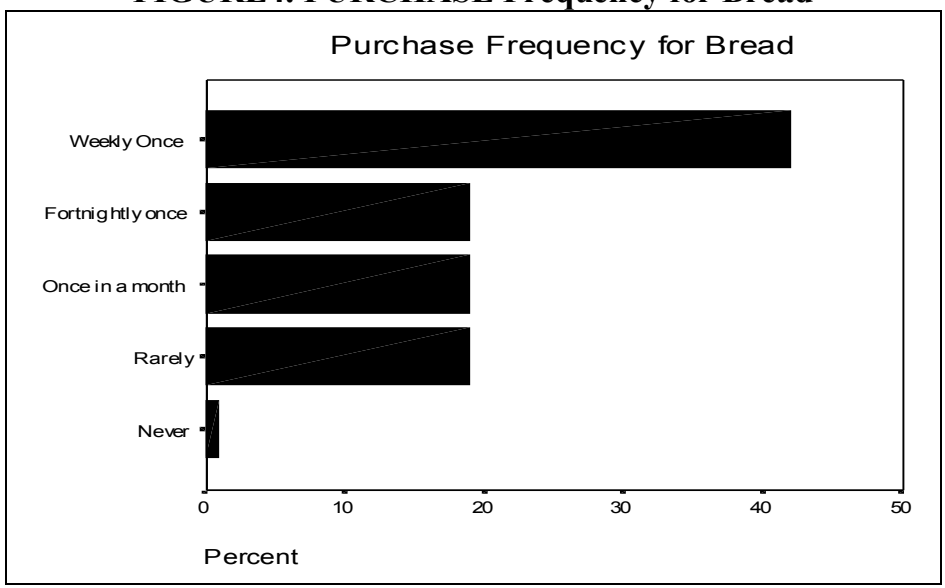

\subsubsection{Rating For Elite Bread}

In response to the query, 'How do you rate Elite bread?' $21 \%$ of the respondents answered Very Good, $50 \%$ answered Good, $21 \%$ found the product satisfactory, while $4 \%$ rated the product unsatisfactory (Table.4).

\begin{tabular}{|ll|r|r|r|r|}
\hline & & & & Cumulative \\
& & Frequency & Percent & Valid Percent & \multicolumn{2}{|c|}{ Percent } \\
\hline Valid & & 4 & 4.0 & 4.0 & 4.0 \\
& very Good & 21 & 21.0 & 21.0 & 25.0 \\
& 50 & 50.0 & 50.0 & 75.0 \\
Good & 21 & 21.0 & 21.0 & 96.0 \\
Satisfactory & 4 & 4.0 & 4.0 & 100.0 \\
Unsatisfactory & 100 & 100.0 & 100.0 & \\
Total & &
\end{tabular}

\section{Conclusions, Limitations \& Recommendations}

To sum up, the study revealed that there was $100 \%$ recognition of the firm and its products. All the respondents had used at least some of the firm's products at some point of time. Elite Sweetbread is the most widely recognized product of the firm, while Elite Round Loaf is the least recognized product.

Of the various bread brands, Elite Fruity Bread was found to be the most popular brand, and had more regular users than others. The $41-60$ years age group represented the highest percentage $(50 \%)$ of regular users of Elite bread brands among all the age groups. White Bread brand is more popular among the Rs.1 lakh - Rs.2 lakh segment than among any other segments. Modern brand bagged the first place with $71 \%$ hits, while Elite brand came a poor second with only $16 \% .81 \%$ of the male respondents voted for Modern brand, while $70 \%$ of the women named Modern bread as the Top of Mind bread brand.

The decisions therefore are equally syncratic and wife dominant. Hence, the focus of target for the firm should be the female population, housewives and workingwomen alike. $42 \%$ of the respondents bought their bread from bakeries. Freshness and good quality are the most sought for attributes for bread. Nearly $42 \%$ of the respondents purchased bread on a weekly basis. Both Elite Sweet Bread and Modern Sweet Bread share 14\% each of the respondent preference share. $21 \%$ of the respondents rated Elite bread Very Good, $50 \%$ answered good, $21 \%$ found the product satisfactory, while $4 \%$ rated the product unsatisfactory.

It is acknowledged that the limitations arising due to small sample size may be present in the study. Errors on the part of the respondents may also occur, while filling in the questionnaire. The respondents may withhold private information or provide a false picture about themselves and their buying decisions and patterns. Due to constraints in time, money and other factors, the study area was restricted to Cochin alone.

The study revealed a number of opportunities for the improvement of the firm's market position. The firm should adopt strategies like cost cutting and quality improvement to attain market leadership in the bread segment. The varieties like Milk Bread and Round Loaf need more advertising to improve brand awareness. Use of the consumer profiles generated by the study will help in creation of superior quality advertisements.

Enlarging the distribution network to ensure quicker and efficient supply of the firm's products, will help in ensuring credibility and increase customer satisfaction. Modern Foods large and efficient distribution is 
its competitive advantage. Incentives should be offered to distributors and retailers, so that the products get maximum display and attract buyer attention. Special attention should be paid to supermarkets, especially in growing cities. Use of promotional techniques such as raffles, freebies, etc., will also help improve sales.

\section{References}

[1]. Ministry of Food Processing Industries website http://mofpi.nic.in/ContentPage.aspx?CategoryId=184 accessed on 15.07.2013

[2]. Upadhyay, Y(1998). 'Consumer Behaviour - An Applied Research Approach’ B.S. Sharma \& Brother's, 1998, 189 pp.

[3]. Krishnamurthy,S , 'Charge of the biscuit brigade', THE HINDU, Sunday, July 30, 2000.

[4]. Peter, J.P. and Olson, J.C. (2005), Consumer Behavior \& Marketing Strategy, 7th ed., McGraw-Hill, New York, NY.

[5]. Howard, J.A. and Sheth, J.N., The Theory of Buyer Behavior, New York, Wiley, 30, 1969

[6]. Engle, James F. and Roger D. Blackwell, Consumer Behavior, Fourth edition, Chicago: The Dryden Press, 1982. 